\title{
Abordagem da temática Aedes aegypti nas escolas de ensino fundamental de Barreirinhas, Maranhão
}

Approach to the theme Aedes aegypti in elementary schools in Barreirinhas, State of Maranhão, Brazil

\author{
Breno Nunes Costa ${ }^{1}$ \\ Bruno Nunes Costa ${ }^{2}$ \\ Dâmaris Rebeca Soares da Silva Carvalho ${ }^{3}$ \\ Luiz Roberto Costa ${ }^{4}$
}

\begin{abstract}
RESUMO
O presente relato de experiência tem por objetivo apresentar informações sobre a realização de um projeto de extensão do curso de Ciências Biológicas, do Instituto Federal do Maranhão, Campus Barreirinhas, que tem por título "Saúde em foco: o combate ao Aedes aegypti no município de Barreirinhas, Maranhão", realizado com estudantes do $6^{\circ}$ ao $9^{\circ}$ do ensino fundamental de escolas municipais. As estratégias metodológicas utilizadas foram palestras, exposições educativas, peça teatral e confecção e distribuição (virtual) de cartilha. Foi alcançado um contingente total de 600 estudantes, sendo esse grupo dividido entre meninos, meninas e até pessoas com deficiências física e visual. Na visão dos educandos, toda a ação de extensão foi muito válida, proveitosa e trouxe muitos conhecimentos sobre o tema problematizado. A atividade de extensão se mostrou muito pertinente e necessária para o processo de formação cidadã dos indivíduos alvos, visto que foi possível apresentar, de uma forma mais diferenciada e dinâmica, um assunto que ainda gera muitas dúvidas aos educandos.
\end{abstract}

Palavras-chave: Aedes aegypti. Atividades de sensibilização. Barreirinhas. Ensino Fundamental.

\begin{abstract}
The present experience report aims to present information about the realization of an extension project by the Biology Sciences course, Federal Institute of Maranhão, Campus Barreirinhas, by the title "Health in focus: combating Aedes aegypti in the municipality of Barreirinhas, Maranhão", carried out with elementary students from the 6th to the 9th years in municipal schools. The methodological strategies used were lectures, educational exhibitions, theater play and production and (virtual) distribution of booklets. A total contingent of 600 students was reached, this group being divided between boys, girls and even people with physical and visual disabilities. In the view of the students, the whole extension action was very valid, profitable and brought a lot of knowledge to the problematic theme. The extension

\footnotetext{
${ }^{1}$ Graduando em Ciências Biológicas no Instituto Federal de Educação, Ciência e Tecnologia do Maranhão, Campus Barreirinhas, Brasil (brenonunescosta3@gmail.com).

${ }^{2}$ Graduando em Ciências Biológicas no Instituto Federal de Educação, Ciência e Tecnologia do Maranhão, Campus Barreirinhas, Brasil (brunonunes.bhs@gmail.com).

${ }^{3}$ Especialista em Enfermagem em Terapia Intensiva pelo Centro Universitário Internacional, Maranhão, Brasil; enfermeira no Instituto Federal de Educação, Ciência e Tecnologia do Maranhão, Campus Barreirinhas, Brasil (damares@ifma.edu.br).

${ }^{4}$ Mestre em Ensino de Ciências e Matemática pela Universidade Federal do Ceará, Brasil; professor efetivo do Instituto Federal de Educação, Ciência e Tecnologia do Maranhão, Campus Barreirinhas, Brasil (luizrobertobiologo@yahoo.com.br).
} 
activity proved to be very pertinent and necessary for the citizen formation process of the target individuals, since it was possible to present, in a more differentiated and dynamic way, a subject that still raises many doubts to the students.

Keywords: Aedes aegypti. Awareness-raising activities. Barreirinhas. Elementary school.

\section{INTRODUÇÃO}

O mosquito Aedes aegypti é o principal vetor das doenças conhecidas como Dengue, Chikungunya, Zika Vírus e Febre Amarela. Esse artrópode apresenta riscos iminentes para saúde humana, uma vez que suas patologias podem acarretar em problemas à fisiologia e morfologia dos indivíduos acometidos por suas enfermidades e, em muitos casos, levando até a morte de diversas pessoas todos os anos nos estados brasileiros, bem como no mundo afora (BRASIL, 2019).

O "mosquito da Dengue", como é conhecido popularmente, tem o seu ciclo de reprodução muito singular, visto que sua proliferação no ambiente é de somente sete dias, ou seja, se a fêmea do inseto depositar ovos em lugar que tenha água parada, e eles, por sua vez, eclodirem na água acumulada, em questão de uma semana os mosquitos juvenis já estão prontos para transmitir seus vírus para os seres humanos (BRASIL, 2019).

No mundo, as ocorrências com Aedes aegypti apresentam maiores registros nos continentes Africano e Americano, tendo em vista que as condições climáticas (tempo úmido e quente) desses lugares propiciam condições mais favoráveis para a reprodução e multiplicação do mosquito em meio às cidades, vilas, povoados e países onde vivem milhões de cidadãos (BARRETO; TEIXEIRA, 1996; VARELLA; JARDIM, 2009).

No Brasil, no ano de 2018, os casos de enfermidades envolvendo o Aedes aegypti foram de: 193.898 para Dengue; 68.835 de Chikungunya e 6.685 referentes ao Zika Vírus, ou seja, as estatísticas em relação aos danos à saúde dos brasileiros ainda são grandes, dado que muitas pessoas ainda sofrem com os ataques e moléstias provocadas pelo mosquito (DANTAS, 2018). No Maranhão, as três doenças apresentaram, juntas, só no ano de 2018, mais de 1.100 casos suspeitos notificados (BRASIL, 2018).

Para o enfrentamento de doenças provocadas pelo A. aegypti e diminuir o índice delas, uma das estratégias é a promoção da Educação em Saúde para população, em especial para aquela parcela que ainda está na educação básica (nível escolar com maior número de estudantes), tendo em vista que esse público ainda está iniciando seu processo de construção e 
aperfeiçoamento do conhecimento, estando, assim, mais aberto para novas informações e conhecimentos sobre determinados problemas que os cercam.

No que diz respeito às ações educativas em saúde sobre prevenção dos males provocados pelo Aedes aegypti, elas devem ser encaradas com prioridade por todos os indivíduos da sociedade, uma vez que pressupõem que as práticas coletivas, voltadas à transformação dos comportamentos e à compreensão sobre determinados malefícios à saúde, resultam de vários fatores determinantes, que envolvem o próprio comportamento social e educacional que os indivíduos constroem ao logo do tempo, a partir de novos conhecimentos (PINTO, 2013; NAKAGAWA, 2013).

A educação em saúde pode ser realizada das mais diversas formas e utilizando uma variedade de materiais. Os métodos mais aplicados, junto aos estudantes da educação básica, para a abordagem de temas ligados ao Aedes aegypti, são a ministração de palestras e apresentações lúdicas de teatro, animação de fantoches e cartilhas ilustrativas. A aplicação dessas metodologias tem por objetivo sensibilizar os estudantes sobre suas atitudes perante um assunto de máxima importância para a vida de todos (SALES, 2008; MENDES, 2014).

Tendo em vista que a temática é atual e a questão educação em saúde se tornou ainda mais pertinente no âmbito do espaço escolar, este relato de experiência tem por objetivo apresentar informações sobre a realização de um projeto de extensão do curso de Ciências Biológicas, do Instituto Federal do Maranhão (IFMA), Campus Barreirinhas, por título "Saúde em foco: o combate ao Aedes aegypti no município de Barreirinhas, Maranhão", realizado com estudantes do $6^{\circ}$ ao $9^{\circ}$ do ensino fundamental de escolas municipais.

O presente relato de experiência se faz relevante, uma vez que servirá para demonstrar à comunidade acadêmica, política e cidadã ser possível promover a sensibilização do corpo estudantil das escolas brasileiras, a partir de atividades consideradas simples, porém muito proveitosas, e, assim, preparar cidadãos preocupados em colaborar com a diminuição do número de casos de doenças provocadas pelo Aedes aegypti no Brasil.

\section{METODOLOGIA}

Optou-se por desenvolver o referido projeto de extensão mediante aprovação em edital interno do IFMA. O público-alvo da ação foram estudantes do $6^{\circ}$ ao $9^{\circ}$ ano das escolas públicas municipais de Barreirinhas, que oferecem ensino fundamental. Os educandos 
contemplados com a atividade extensionista foram divididos entre quatro escolas, dos mais diversos bairros da zona urbana da cidade.

A equipe multidisciplinar extensionista foi formada por dois profissionais de Biologia, uma Pedagoga, uma Enfermeira, uma Técnica de Enfermagem e um Técnico em Informática e sete educandos extensionistas (três do ensino superior e quatro do ensino médio).

A ação de extensão foi dividida em 6 etapas, conforme descrito abaixo:

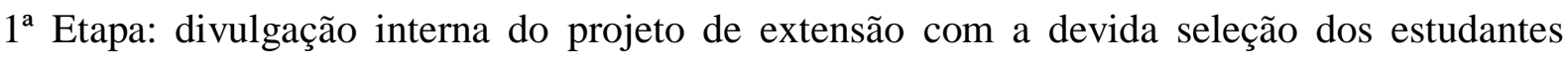
extensionistas (um mês);

$2^{\text {a }}$ Etapa: capacitação técnica da equipe de extensão, mediante leitura de periódicos (no que tange ao combate ao Aedes aegypti), além da preparação de materiais para a ministração de palestras, peça teatral e exposições didáticas (um mês);

$3^{\text {a }}$ etapa: visitas às escolas alvo do projeto de extensão, a fim de agendar e autorizar cada palestra, peça teatral e exposições didáticas (um mês);

$4^{\mathrm{a}}$ Etapa: execução das palestras, peça teatral e exposições nas escolas alvo da extensão (cinco meses);

5 Etapa: criação e distribuição digital, via WhatsApp, da Cartilha sobre o combate ao Aedes aegypti (um mês).

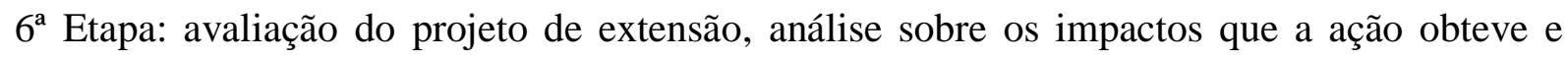
produção de relatório final sobre o ato extensionista (um mês).

Ressalta-se que na quarta etapa, foram utilizadas maquetes sobre o mosquito Aedes aegypti, garrafas plásticas, bacias, água sanitária, pneus, slides em Powerpoint, notebook e peça teatral. Além disso, os registros fotográficos presentes neste relato de experiência, foram autorizados pela direção/coordenação de cada escola participante, tendo em vista que se faziam necessários até mesmo para comprovar a realização da atividade de extensão, bem como para divulgação da ação pelas mídias sociais.

\section{RESULTADOS}

Os resultados das atividades de extensão são de suma importância para a discussão a que se referem a práticas de educação em saúde dentro das unidades de ensino brasileiras, tendo em vista que esses ambientes podem ser considerados estratégicos para a realização de ações de 
sensibilização sobre as mais diversos temas que envolvem a saúde e a qualidade de vida dos estudantes e sociedade como no todo.

A atividade intitulada "Saúde em foco: o combate ao Aedes aegypti no município de Barreirinhas, Maranhão", teve por público atendido um total de 600 estudantes das séries finais $\left(6^{\circ}\right.$ ao $9^{\circ}$ ano) do ensino fundamental, sendo esse contingente dividido entre meninos e meninas, incluindo pessoas com deficiências física e visual. A faixa etária de idades dos educandos foi de 11 a 15 anos.

Das escolas participantes, apenas uma não possuía espaço suficiente e adequado para concentração de plateia e realização das palestras, peça teatral e exposição educativa, para isso os educandos foram levados, por meio de ônibus cedido pela prefeitura, até o auditório do Instituto Federal do Maranhão, Campus Barreirinhas.

As escolas alvo apresentavam materiais e estruturas consideradas adequadas, como salas de aulas climatizadas (ar-condicionado), carteiras em perfeito estado, retroprojetores, computadores, internet, microfone e caixa de som, porém arquitetura ultrapassada (modelos prediais estilo "escola-presídio", tipo anos 1950 e 1960), além de uma delas possuir espaços muitos pequenos para o convívio dos discentes.

\section{Realização de palestras}

Como forma de sensibilizar os estudantes contra os males causados pelo mosquito Aedes aegypti, realizou-se uma série de palestras para educandos do ensino fundamental dos anos finais, por meio da temática "Aedes aegypti: conhecendo e combatendo". Foram apresentadas informações pertinentes sobre a origem do mosquito e suas características corporais, bem como as doenças e sintomas provocadas por ele, além dos tratamentos aplicados para as enfermidades, modo de prevenção dos focos e outras curiosidades sobre o tema.

Os assuntos das palestras foram ministrados sempre com auxílio de retroprojetor e notebook, mediante exibição de imagens e slides para melhor compreensão do que estava sendo falado. Ao final de cada palestra ministrada, foram abertos momentos de perguntas, uma espécie de "tira dúvida", no qual os estudantes tiveram a oportunidade de realizar indagações sobre o tema exposto. Para essa etapa, o palestrante, junto com a equipe multidisciplinar, responderam às dúvidas de todos (Imagens 1, 2 e 3). 
Imagens 1, 2 e 3 - Palestras com os estudantes das escolas

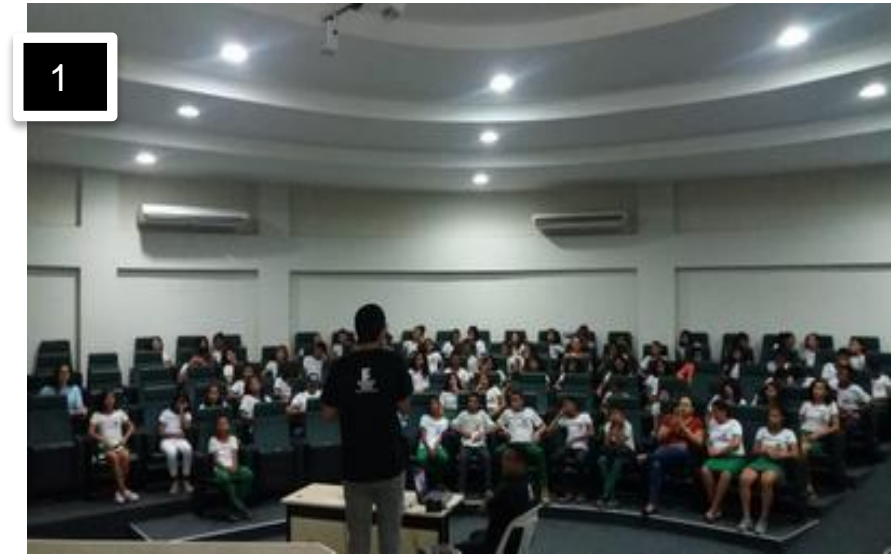

Fonte: Acervo do projeto (2019)

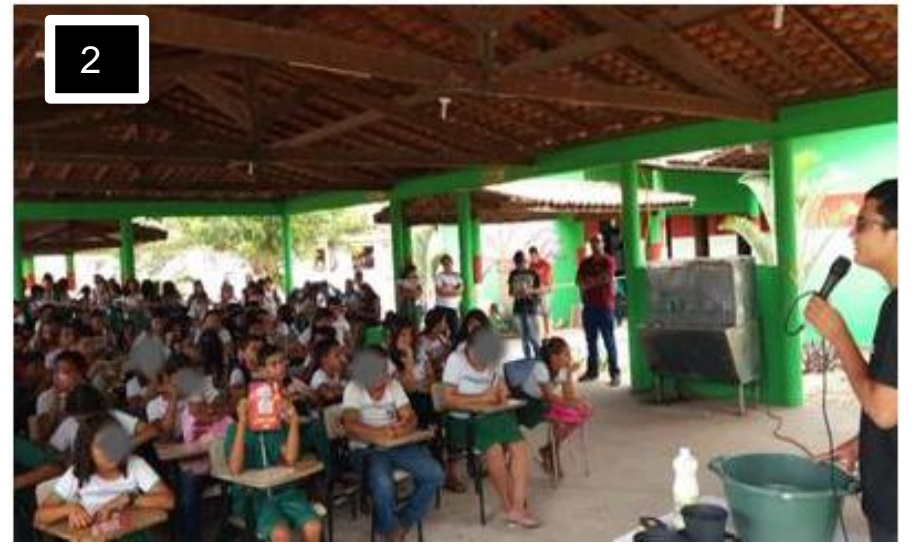

Fonte: Acervo do projeto (2019)

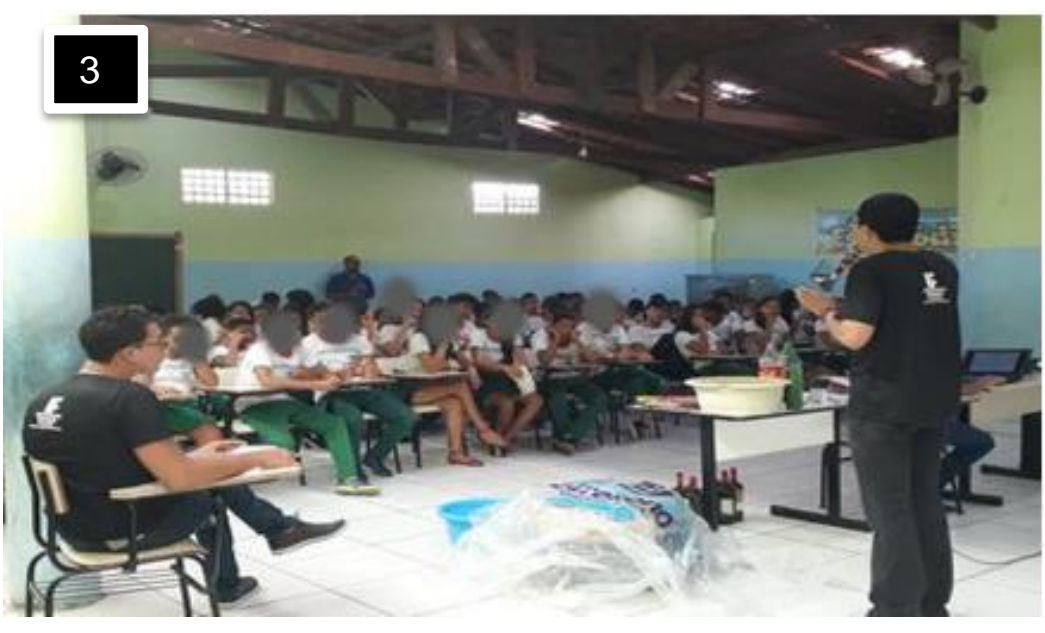

Fonte: Acervo do projeto (2019)

Os estudantes mostraram-se interessados no tema. Foi perceptível observar a atenção que a maioria deu a cada tela apresentada e fala expressada pelo palestrante, além da vasta participação deles no momento do "tira dúvida", com indagações feitas, muitas vezes, utilizando parte daquilo exposto no decorrer da atividade como contexto para suas indagações. Esse fenômeno também foi observado pelos próprios educadores dos educandos, após conversas pessoais com alguns docentes.

\section{Exposições educativas}

Como forma de transpassar e obter um conhecimento mais preciso e completo sobre o que é repassado de forma teórica, também foram realizadas exposições educativas sobre o tema problematizado, sendo expostos, nos pátios das escolas, maquetes de mosquito Aedes aegypti, macho e fêmea, a fim de demonstrar as características e diferenças morfológicas e 
comportamentais entre os dois. Outros materiais como pneus, bacias, água sanitária, escovas, garrafas PET, litros de vidro e lona de plástico também foram colocados à mostra.

Nas exposições, foram explicados o que fazer com os resíduos presentes nos quintais e locais abertos das casas dos estudantes, a forma correta de lavar, o que utilizar na limpeza das superfícies dos reservatórios de águas, e sobre a frequência que essas ações devem ser realizadas para evitar criadouros de larvas e mosquitos do Aedes aegypti (Imagens 4, 5 e 6).

\section{Imagens 4, 5 e 6 - Exposições educativas com os estudantes das escolas}

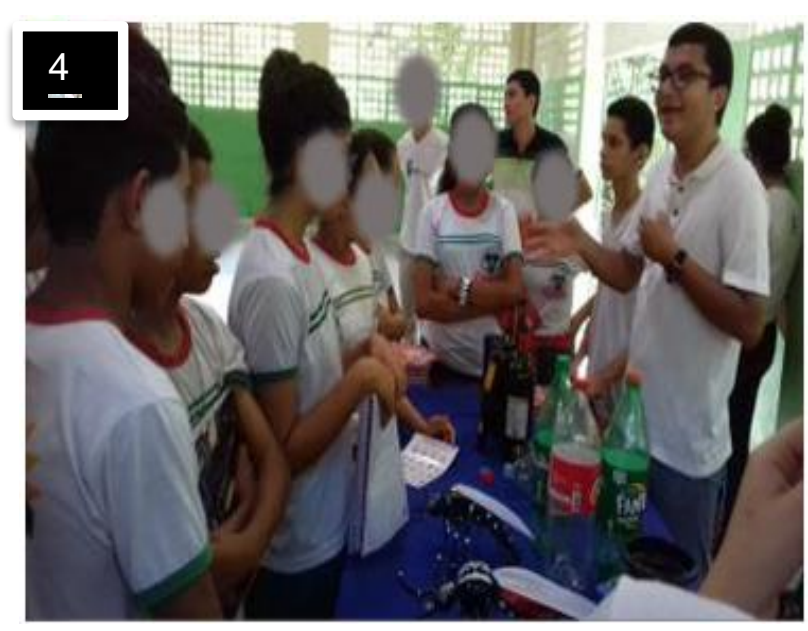

Fonte: Acervo do projeto (2019)

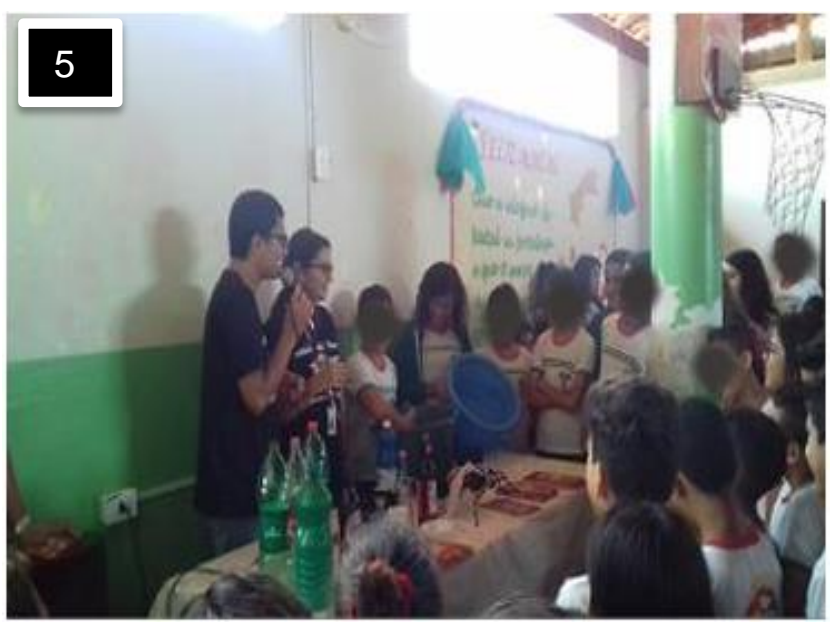

Fonte: Acervo do projeto (2019)

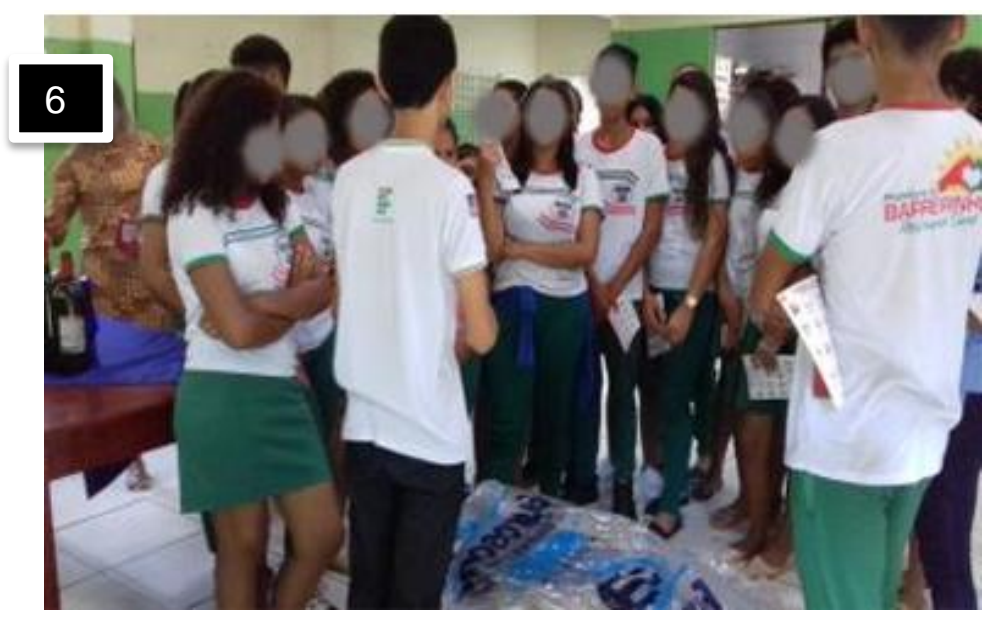

Fonte: Acervo do projeto (2019)

Segundo alguns estudantes ouvidos, a exposição educativa proporcionou-lhes mais conhecimentos sobre o tema, tendo em vista que muitas dúvidas foram sanadas sobre o mosquito Aedes aegypti, bem como sobre as ações de limpeza que os recipientes que armazenavam água parada deveriam passar em quintais e locais abertos. 


\section{Peça teatral e cartilha educativa}

A peça teatral, apresentada ao final das palestras, e a cartilha educativa, confeccionada pela equipe de extensão e distribuída via WhatsApp à comunidade escolar, tiveram por objetivo auxiliar o processo de sensibilização que estava sendo desenvolvido pelo projeto de extensão. Todo o contexto da peça teatral e da cartilha baseou-se em uma narrativa própria criada pela equipe de extensão, sendo aplicada, na escrita, uma linguagem de fácil entendimento e popular. O enredo narrativo conta a história de uma mulher que possuía um quintal muito mal cuidado, desorganizado e cheio de resíduos sólidos (plásticos, pneus, garrafas PET e outros recipientes) que acumulavam água parada, propiciando ambiente adequado para a reprodução do Aedes aegypti. Certo dia, "um casal terrível" bate em sua porta, os dois eram o senhor e a senhora Aedes, e estavam em busca de um local para se reproduzirem, e acharam essa possibilidade na residência da dona da casa. A dona da casa ficou extremamente assustada com a visita e com as palavras do casal. Já desesperada, uma vez que o casal já havia entrado em sua residência, mais precisamente no seu quintal, ela ouviu novamente um batido em sua porta e abriu, era uma agente de saúde que viera fazer uma visita periódica. A mulher contou o que estava havendo, e rapidamente a servidora orientou a senhora sobre o que deveria ser feito para mandar o casal embora. O quintal foi organizado, a água parada foi derramada e o “casal terrível” acabou se despedido muito triste (Imagens 7 e 8).

\section{Imagem 7 - Peça apresentada aos estudantes das escolas}

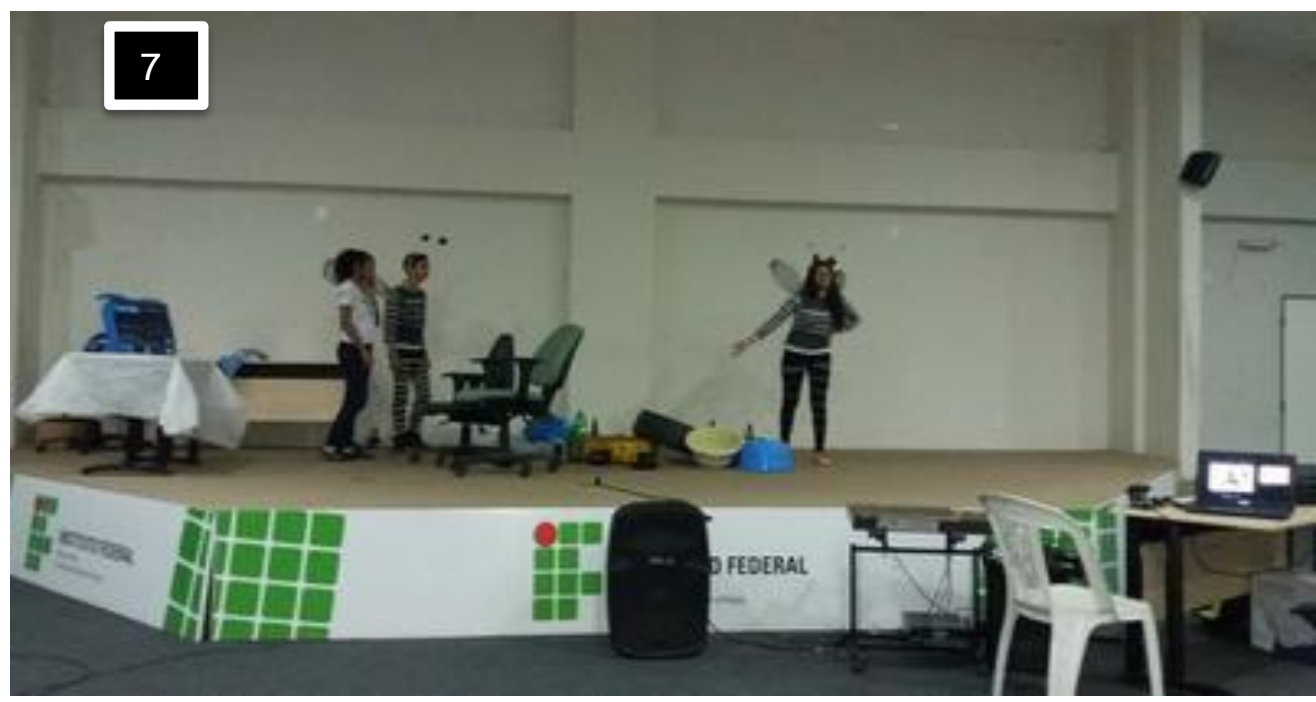

Fonte: Acervo do projeto (2019) 
Imagem 8 - Cartilha distribuída via internet

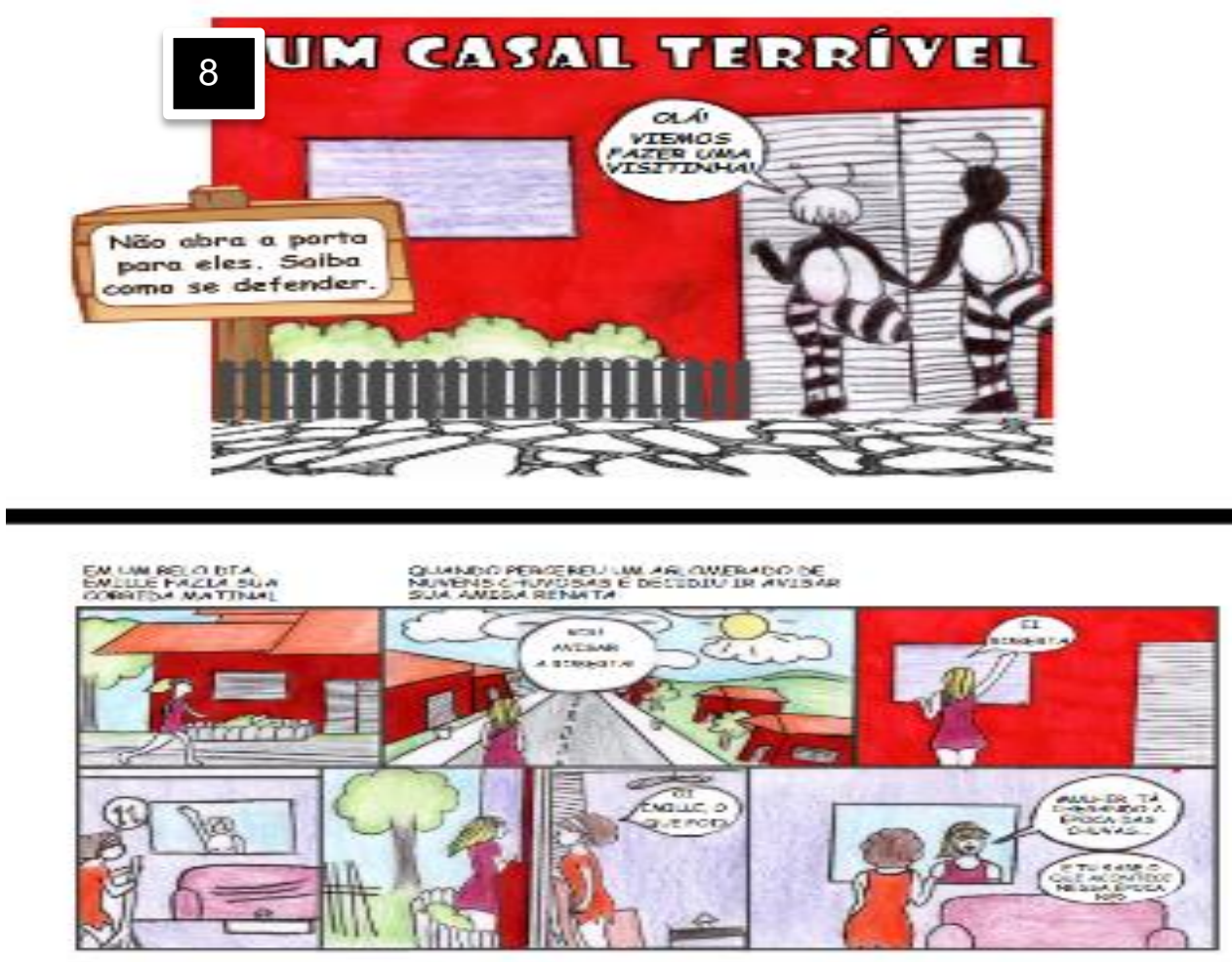

Fonte: Acervo do projeto (2019)

Os estudantes ficaram muito animados com a apresentação, mostrando-se atenciosos com cada parte do enredo apresentado pela peça teatral. De acordo com alguns deles, ouvidos ao final de cada apresentação, foi possível compreender, de forma mais divertida e diferenciada, o assunto apresentado, visto que a atividade trouxe uma abordagem muito mais atraente, chamativa e explicativa sobre o tema.

\section{CONSIDERAÇÕES FINAIS}

O projeto de extensão atendeu ao objetivo de sensibilizar os educandos das escolas de Ensino Fundamental, em destaque os anos finais $\left(6^{\circ}\right.$ ao $9^{\circ}$ ano), sobre as questões de educação em saúde, mais precisamente no que se diz respeito à temática Aedes aegypti. Mostrou-se muito pertinente e necessário para o processo de formação dos indivíduos alvos, visto que foi possível apresentar, de uma forma mais diferenciada e dinâmica, um assunto que ainda gera muitas dúvidas aos educandos. 
As atividades de palestras, peça teatral, exposição educativa e confecção e distribuição de cartilha digital, juntas, apresentaram-se como uma forma mais agradável e lúdica para a realização de ações de sensibilização. A associação dessas ferramentas metodológicas são estratégias utilizadas, muitas vezes, separadamente, mas, no projeto de extensão, foram aplicadas conjuntamente como forma de atrair um número maior de estudantes para uma problemática ainda muito pertinente no dia a dia de todos.

\section{REFERÊNCIAS}

BARRETO, M. L.; TEIXEIRA, M. G. Porque devemos, de novo, erradicar o Aedes Aegypti. Ciênc. saúde coletiva, Rio de Janeiro, v. 1, n. 1, 1996. Doi: 10.1590/1413812319961101582014.

BRASIL. Instituto Oswaldo Cruz. Como é o ciclo de vida do mosquito Aedes aegypti? 2019. Disponível em: https://portal.fiocruz.br/pergunta/como-e-o-ciclo-de-vida-do-mosquitoaedes-aegypti. Acesso em: $1^{\circ}$ mar. 2020.

BRASIL, Ministério da Saúde. Combate ao Aedes Aegypti: prevenção e controle da dengue, chikungunya e zika. 2019. Disponível em: https://saude.gov.br/saude-de-a-z/aedes-aegypti. Acesso em: $1^{\circ}$ mar. 2020.

BRASIL, Ministério da Saúde. Maranhão: 169 municípios em situação de alerta ou risco para dengue, zika e chikungunya. 2018. Disponível em: https://www.saude.gov.br/noticias/agencia-saude/43498-maranhao-registra-169-municipiosem-situacao-de-alerta-ou-risco-para-dengue-zika-e-chikungunya-2. Acesso em: $1^{\circ}$ mar. 2020.

DANTAS, C. Brasil tem queda de até $60 \%$ nos casos de doenças do Aedes, mas dengue ainda atinge 193 mil pessoas. 2018. Disponível em: https://g1.globo.com/bemestar/aedesaegypti/noticia/2018/09/01/brasil-tem-queda-de-ate-60-nos-casos-de-doencas-do-aedes-masdengue-ainda-atinge-193-mil-pessoas.ghtml. Acesso em: $1^{\circ}$ mar. 2020.

VARELLA, D.; JARDIM, C. Dengue e febre amarela: guia prático de saúde e bem-estar. São Paulo: Gold, 2009.

MENDES, F. M. S. Brincar e aprender: a importância do lúdico para as crianças. 2014. 38 f. Monografia (Especialização em Educação: Métodos e Técnicas de Ensino) - Universidade Tecnológica Federal do Paraná, Curitiba, 2014.

NAKAGAWA, C. Promoção da saúde nas ações de controle e combate ao dengue nas escolas de Ceilândia. 2013. 68 f. Monografia (Bacharelado em Saúde Coletiva) Universidade de Brasília, Ceilândia, 2013.

PINTO, M. J. M. Eficiência do diflubenzuron nas ações de controle do vetor do dengue: Aedes aegypti. Além Paraíba, 2013. Monografia (Especialização em Gestão Ambiental) Faculdade de Ciências da Saúde Archimedes Theodoro, Fundação Educacional de Além Paraíba, 2013. 
SALES, F. M. Ações de educação em saúde para prevenção e controle da dengue: um estudo em Icaraí, Caucaia, Ceará. Ciência \& Saúde Coletiva, Rio de Janeiro, v. 13, n. 1, p. 175-184, 2008. Doi: 10.1590/S1413-81232008000100022.

Submetido em 2 de março de 2020.

Aprovado em 14 de abril de 2020. 